\title{
Blood Pressure Control and Protection of the Aging Brain
}

\author{
Nasratullah Wahidi ${ }^{1} \cdot$ Alan J. Lerner ${ }^{1,2}$ (I) \\ Published online: 3 June 2019 \\ (C) The American Society for Experimental NeuroTherapeutics, Inc. 2019
}

\begin{abstract}
Hypertension and dementia are both common disorders whose prevalence increases with age. There are multiple mechanisms by which hypertension affects the brain and alters cognition. These include blood flow dynamics, development of large and small vessel pathology and diverse molecular mechanisms including formation of reactive oxygen species and transcriptional cascades. Blood pressure interacts with Alzheimer disease pathology in numerous and unpredictable ways, affecting both $\beta$-amyloid and tau deposition, while also interacting with $\mathrm{AD}$ genetic risk factors and other metabolic processes. Treatment of hypertension may prevent cognitive decline and dementia, but methodological issues have limited the ability of randomized clinical trials to show this conclusively. Recent studies have raised hope that hypertension treatment may protect the function and structure of the aging brain from advancing to mild cognitive impairment and dementia.
\end{abstract}

Key·Words Hypertension · Dementia $\cdot$ Cognition $\cdot$ Aging $\cdot$ Alzheimer's disease $\cdot$ Mild cognitive impairment

\section{Introduction}

Blood pressure (BP) is a central regulatory process essential for homeostatic control of the living organism. BP is the force necessary to move blood forward so that glucose and oxygen delivery is adequate and waste products are eliminated via the venous system.

The aging brain is susceptible to many insults related to BP control. These can be roughly divided into direct effects and indirect effects, and acute versus chronic changes as well. Examples include acute hypertension or hypotension, blood vessel injury due to atherosclerotic disease related to chronic hypertension, or lack of nutrient delivery. Indirect effects include brain stressors such as oxidative stress or inflammation. In this article, we review the effects of hypertension and BP control on the aging brain, with special attention to dementia prevention through BP control.

Alan J. Lerner

Alan.lerner@uhhospitals.org

1 Department of Neurology, University Hospitals Cleveland Medical Center, 11100 Euclid Avenue, Cleveland, OH 44106, USA

2 Case Western Reserve University School of Medicine, Cleveland, OH 44106, USA

\section{Epidemiology of Hypertension}

Worldwide, hypertension affects more than 1 billion people [1] and the majority of about 639 million live in the developing world [2]. Twenty-nine percent of American adults suffer from hypertension [3]. When this number is further broken down by gender and age, Americans over the age of 60 years make up the largest percentage of the hypertensive population [3]. The second largest cohort is persons age 40 years and older. Men have higher rates of hypertension until the age of 60 years after which more women suffer from hypertension [3], possibly due to differential survival bias. The prevalence of hypertension increased with age but the overall prevalence remained unchanged from 1999 to 2016 [3]. When the prevalence of hypertension is broken down by race, non-Hispanic blacks make up the largest group followed by non-Hispanic whites and Hispanics and with the lowest prevalence in nonHispanic Asians [3].

About $48.3 \%$ of Americans who suffered from hypertension had pharmacologically treated blood pressure control in the year from 2015 to 2016 . The prevalence of treated hypertension increased with age with the highest prevalence in Americans over age 60 years and lowest between ages 18 to 39 years [3]. Non-Hispanic whites and women had higher rates of blood pressure control compared to men and nonHispanic blacks [3]. Although the prevalence of pharmacological BP control increased from 1999 to 2010, no increase in the prevalence of BP control was noted from 2010 to 2016. 


\section{Basic Science Aspects}

Several possible mechanisms have been postulated to explain the possible association between BP and cognition, including one hypothesis that chronic hypertension may cause oxidative stress, which leads to endothelial dysfunction, which in turn may result in dysfunction of the arteries and small vessels of the brain vasculature $[4,5]$.

Blood flow is the result of five major components: cardiac output, blood vessel compliance, intravascular volume, blood viscosity, and vessel length and diameter. These components are in turn regulated via multiple organ systems (kidney, heart, endocrine), neurohormonal control (anti-diuretic hormone), and fluid intake. One component that becomes more important with aging are the changes in the elastic properties of the blood vessels. Arterial wall stiffening, is functionally equivalent to reduced elasticity, and multiple studies have associated hypertension with increases in arterial wall stiffening with cognitive impairment [6-8]. As discussed below, older people in the intensive BP treatment arm of the SPRINT study showed an increase in the incidence of syncope possibly due to decreased vessel wall compliance [9]. Blood vessel length also affects both resistance and blood flow. During adulthood, the total body vessel length remains generally stable unless there is significant weight gain or loss $[8,10,11]$.

Besides the abovementioned mechanism for BP control which can result in a hypertensive state, other systems have also been implicated in BP control such abnormal T-cell function, reactive oxygen species, and antioxidants for the development of hypertensive states [12-14]. Hypertensive disease usually develops over many years and is associated with increases in excess reactive oxygen species (ROS) throughout the body $[14,15]$. Other causes of ROS production are hypoxic states in which tissue injury is mediated by a large number of activated transcription factors, regulators of signal transduction, and induction of defense genes [14]. ROS have been shown to affect the vascular tone, endothelial function, inflammation, and other important functions involved in end organ structures [13-15].

\section{Definition of Vascular Cognitive Impairment}

Cognitive impairment is variously defined and is recognized to be both heterogeneous in etiology, clinical presentation, and appearance on imaging. One limitation of clinical studies has been the variability on the definition of vascular dementia (VaD). The NINDS-AIREN criteria have been widely used in clinical studies. However, it includes large vessel infarcts, single strategically placed infarcts, multiple basal ganglia and subcortical lacunar infarcts, and "extensive" periventricular white matter lesions as causes of $\mathrm{VaD}$. Hachinski and colleagues have introduced the concept of Vascular Cognitive Impairment (VCI) as an analog of mild cognitive impairment
(MCI) $[16,17]$. The relationship of VCI to the sub-classes of $\mathrm{VaD}$ etiology is not well defined, but seems most appropriate for subjects with extensive white matter lesions which present as $\mathrm{VaD}$ with insidious onset $[16,17]$.

\section{Randomized Clinical Trials of BP Control and Preventing Cognitive Decline}

The relationship between blood pressure control and improving cognition or more commonly, reducing the risk of cognitive decline is complex. Studies looking at this question have had conflicting results. Some studies such as ACCORD, which measured hypertension control in persons with diabetes, did not show a reduction in dementia risk but did show a reduction in slowing white matter lesion progression [18, 19], whereas other studies in which blood pressure was very tightly controlled at or below $120 / 80 \mathrm{mmHg}$ noted a reduction in the risk of developing cognitive decline [9]. The role of hypertension is further muddled in cognitive decline when the age of the person is taken into account. In some studies, it is noted that in persons over the age of 90 , hypertension is associated with reductions in cognitive decline [20-23].

\section{Systolic Hypertension in Europe Study}

The Systolic Hypertension in Europe (Syst-Eur) was one of the first double-blind studies followed by an open-label study that aimed at dementia prevention. The study was terminated early in 1997 because the primary outcome of stroke showed a significant reduction with BP control. Syst-Eur showed a reduction in the incidence of dementia by $50 \%$ from 7.7 to 3.8 cases/1000 subjects/year, but there were only 32 incident cases overall, limiting the result's interpretation. In a followup study, the incidence of dementia cases was increased to 64 cases with 41 persons having Alzheimer's disease (AD). The study concluded that for 1000 patients treated with nitrendipine, an additional 20 cases of dementia were prevented [24].

The limitation of the Syst-Eur study include the use of a single agent nitrendipine which is not available in the USA, and limited duration of the study. The absolute number of cases was small, especially in the relatively short doubleblind phase, and it has been suggested that the practical benefits were therefore of limited value [24]. However, as proof of concept, Syst-Eur remains an important landmark, and some of the experiences from that study have been repeated in later studies, such as early termination of both HYVET and SPRINT.

\section{Hypertension in the Very Elderly Trial (HYVET) Study}

The HYVET study enrolled 4761 subjects throughout Europe, China, Tunisia, Southeast Asia, and Australia, over age 
80 years. 3336 subjects of 3781 randomized had at least two visits and a mean follow-up of 2.2 years. The main study was again terminated early because interim analysis showed benefit, with reductions in mortality, stroke, and heart failure. The study itself did not show a significant dementia risk reduction based on 263 cases of incident dementia. The results were suggestive of an emerging effect, but the short follow-up precluded it from reaching statistical significance. However, when data were combined in a meta-analysis of other placebo-controlled studies, the combined risk ratio favored treatment over placebo $(\mathrm{HR}=0.87,95 \%$ CI $0.76-1.0$ and $p=0.045)[25]$.

\section{SPRINT and SPRINT-MIND}

SPRINT was designed to compare the effectiveness of two different blood pressure targets, namely 120/80 mmHg (intensive treatment) versus $140 / 90 \mathrm{mmHg}$ (standard treatment) [9, 26]. The study subjects were age 50 years and above and known to have increased Framingham cardiovascular risk scores, or subclinical risk with chronic kidney disease stage 3 , defined as a glomerular filtration rate 40 to $60 \mathrm{~mL} / \mathrm{min} /$ $1.73 \mathrm{~m}^{2}$. The study enrolled 9361 subjects and included an expanded cohort $>75$ years in age. The main study was stopped prematurely in 2015 after positive results of analyses showed reductions in the composite endpoint of cardiovascular events and mortality favoring intensive BP control.

SPRINT-MIND occurred in several phases and the subjects were followed for a median of 3.3 years [26]. The primary prespecified outcome was a reduction in incident all-cause dementia. Dementia occurred in 149 subjects, and was not statistically significant between groups. Analyzing mild cognitive impairment and dementia showed significant differences favoring intensive BP control (20.2 vs 24.1 cases per 1000 person years; hazard ratio $0.85 ; 95 \%$ confidence interval 0.74 to 0.97 ). The disparity between dementia and mild cognitive impairment was probably due to the low event rate because the main study was stopped earlier than originally planned, due to positive findings with regard to cardiovascular events, as has been seen in previous anti-hypertensive studies described above.

The MRI findings from SPRINT-MIND involved a subset of subjects given a brain MRI at baseline and the study conclusion [27]. The findings of the primary analyses have been published in abstract form. It showed a significantly smaller increase in total brain white matter lesion volume favoring intensive treatment. Changes in total brain volume were larger in the intensive treatment group [27]. The reasons for this were unclear, and the findings indicated a significant gender difference in total brain volume change, but not in total white matter lesion volume change. Brain volume changes in women favored intensive treatment, the opposite of what was found in males. The underlying etiology for these changes in brain volume and gender differences is also unknown.

The findings from SPRINT-MIND are notable for several reasons. This is the first large study to show the value of vascular risk factor reduction in preventing cognitive decline (functionally defined as mild cognitive impairment). Mild cognitive impairment is the prodrome for both vascular cognitive impairment due to extensive white matter disease, as well as primary degenerative dementias such as AD. It can only be surmised that had the study continued, the differences in incidence of mild cognitive impairment would translate into lowered dementia risk with intensive BP control. The clinical findings also found a structural correlate in the volume of white matter lesions with smaller increases over several years in the intensive BP control group. As discussed below, the relationship of small vessel disease, the main underlying pathology of white matter disease to cognition is complex, but all of the findings seem concordant with the popular mantra that "What is good for the Heart is also good for the brain" [28].

\section{Specific Anti-hypertensives and the Aging Brain}

A frequently asked question is whether specific antihypertensives confer special protection on the aging brain? The ability to answer this question is difficult, partly because available data is mostly derived from clinical trials, which have not always matched specific classes of pharmaceuticals against each other. These clinical trails have limitations in their own right, as shown in the previous section.

Sink et al. (2009) reported results from the Cardiovascular Health Study-cognition sub-study [29]. Compared to other anti-hypertensives, there was no association of ACE inhibitors and incident dementia risk, difference in 3MSE scores, or odds of developing disability in instrumental activities of daily living (IADL). Even in the same study, however, centrally active ACE inhibitors were associated with $65 \%$ less decline in $3 \mathrm{MSE}$ scores, whereas peripherally acting ACE inhibitors were associated with greater risk of incident dementia. In the Ginkgo Evaluation of Memory study, 3069 non-demented subjects over age 75 were studied. About $35 \%$ had a history of hypertension and spread between diuretics, ACE inhibitors, and angiotensin-2 receptor blockers. Potassium-sparing diuretic use was associated with better verbal learning and memory function, whereas the other two classes showed no difference from those subjects not taking anti-hypertensives [30].

In a review of human studies, Hughes et al. [31] noted a linked between midlife hypertension and cognitive decline later in life. However, the link between elevated BP in older persons and subsequent cognitive decline was inconsistent; the link between elevated BP and cognitive decline become more apparent in older persons when systolic BP (SBP) was elevated above $180 \mathrm{mmHg}$. In observational studies, Hughes 
et al. noted a linear association between midlife elevated SBP and cognitive decline, and the association was stronger for Caucasian populations compared to African-Americans [31]. Persons with elevated SBP were noted to have reduced total brain size with a reduction in volume in dementia-associated regions such as the hippocampus [31]. The reduced brain size was evident even if the subjects were treated with antihypertensives [32]. Another interesting finding in Hughes et al. review was that in older persons, lowered BP was associated with reductions in brain size, and lower diastolic BP was associated with cortical thinning [31]. The exactly etiology for these findings is unknown but caution should be taken in concluding that aggressive BP control in the older persons only produces negative effects on the brain.

\section{Structural Changes in the Brain in Hypertension Studies}

The development of new imaging modalities in recent years has added a new dimension to our understanding of hypertension effects on the brain. In the PROGRESS study, hypertensive persons had increased white matter intensities on MRI, and when BP was controlled there was a reduction in the number of white matter intensities on the Magnetic Resonance Imaging (MRI) [32]. In this study hypertensive persons also showed increased frequency of vascular amyloid deposition [32].

\section{Small Vessel Disease and the Aging Brain}

Small vessel disease (SVD), a heterogonous group of disorders, is a known risk factor for cognitive impairment and a cause of dementia [33]. Small vessel disease is best defined pathologically, although this includes a variety of microscopic findings including reduced vessel caliber, reduced vessel number, lipohyalinosis, and small cerebral infarcts. Vessel caliber is itself non-specific and may be related to lipohyalinosis, amyloid angiopathy, thrombosis leading to ischemia and infarction, and other causes [34-36].

Adding to the confusion around the meaning, causes, and manifestations of SVD is the non-specific nature of leukoariaosis (sometimes spelled leukoariosis) seen commonly on MRIs especially in middle-aged and older individuals. Evidence of small vessel disease found on MRI may relate to various findings: small lacunar infarcts, primary demyelinating lesions caused by many inflammatory diseases of the CNS, and periventricular or deep white matter lesions, with or without brainstem lesions. The most common locations for small vessel disease lesions include the frontal lobe, basal ganglia, and thalamo-cortical areas of the brain [34]. SVD may also be related to changes in specific white matter tracts such as are commonly seen early in degenerative disorders, affecting the inferior fronto-occipital fasciculus and causing white matter changes adjacent to the cerebral ventricles [37].
SVD can either be clinically silent or clinically significant depending on the location, etiology, and volume of the lesion. The changes noted in SVD may occur with normal aging in 40 to $50 \%$ of brain MRIs in midlife or older adults [38, 39]. The hyperintensities are much more diverse in normal aging than those seen with pathological conditions such as lacunar stroke presenting as SVD on MRI [38-40]. These lesions can be found as early as midlife and in association with multiple etiologies: aging, hypertension, diabetes, migraine, stroke, and barotrauma [40]. Other SVD risk factors include metabolic abnormalities, renal disease, tobacco smoking, elevated homocysteine levels, and alcohol use [40-42].

Symptomatic SVD can manifest itself in multiple ways such as micro-hemorrhage or lacunar infarcts. Over time, there is an accumulative effect from the collection of lesions leading to multiple neurological symptoms and ultimately contributing to vascular dementia [42-45]. Although SVD in itself can lead to dementia, it can also contribute as a significant comorbidity to other neurodegenerative processes (e.g., AD), and leading to multifactorial mixed dementia, which is particularly common in older persons [43, 45].

SVD can present on MRI either as white matter hyperintensities on T2-weighted and FLAIR sequences, or circular hypointensities on gradient echo/susceptibility weighted images known as microbleeds [46]. Microbleeds are usually $5 \mathrm{~mm}$ or less in diameter with a variable relationship to cognitive impairment. Thus, they range from a single asymptomatic lesion to dozens or even hundreds of lesions, especially in persons with advanced cerebral amyloid angiopathy (CAA). CAA is often considered as a pathological form of small vessel disease, but is beyond the resolution of MRI, and often diagnosed indirectly based on microbleeds or symptomatic cerebral hemorrhage in older individuals occurring in locations not considered typical for hypertension-related cerebral hemorrhage $[34,46]$. The presence of $>4$ microbleeds has been associated with amyloid-related imaging abnormalities (edema or hemorrhage), and may be symptomatic in the setting of amyloid-lowering drugs, and occurs especially in those with an APO E e4 allele [47].

The pathological features of SVD at the microscopic level are variable, and besides amyloid angiopathy, these changes often include gliosis, enlarged perivascular spaces, myelin pallor, and changes to the ependymal lining [42-44]. These processes are associated with axonal demyelination and rarefaction of axons in the cerebral white matter. As the SVD burden increases over long periods of time, there is a correlation with increased cortical and hippocampal neuronal loss leading to global atrophy. MRI cannot detect neuronal loss which is the hallmark of atrophy, but is very sensitive to reductions in parenchymal volume, and FLAIR sequences are very sensitive to changes in white matter, albeit nonspecific as to etiology [34, 43, 44, 48, 49]. 


\section{Genetic Forms of Small Vessel Disease}

There are a number of genetic disorders, presenting as apparent vascular dementia with SVD. Most notable among them is cerebral autosomal dominant arteriopathy with subcortical infarcts and leukoencephalopathy (CADASIL). CADASIL presents with a constellation of symptoms, including longstanding migraines with aura, motor symptoms, and ultimately vascular dementia due to strokes with early onset of cognitive symptoms in the late $40 \mathrm{~s}$ to $50 \mathrm{~s}$. Neuroimaging of CADASIL shows extensive small vessel disease with a high burden of white matter hyperintensities and subcortical infarcts [50]. Histological findings of CADASIL include thickening of the small vessels. Genetic testing reveals mutations in the Notch 3 gene with inheritance in an autosomal dominant pattern. Rare cases of an autosomal recessive disorder known as CARASIL have also been reported [50, 51]. Another genetic form of small vessel disease is Fabry disease, an Xlinked disorder which belongs to the class of disorders collectively knowns as lysosomal storage disorders. Fabry disease (also known as Anderson-Fabry disease) is caused by a deficiency in alpha-galactosidase, which is required to break down sphingolipids. As sphingolipids accumulate, they deposit in the blood vessel wall affecting multiple organ systems. In the brain, the disorder manifests itself as multiple infarcts in both small and large blood vessels alongside diffuse white matter changes [51, 52].

\section{Life Style Modification}

Besides direct control of hypertension through pharmacological interventions, another area that may reduce the risk of dementia/cognitive decline and the development of hypertension are collectively called lifestyle modifications [53]. These lifestyle modifications include a balanced heart-healthy diet, physical and cognitive exercises, weight loss, social engagement, improving sleep quality, and absence of tobacco and limited alcohol use [53, 54]. One might believe that cognitive exercises such as games requiring attention and memory or reading would have clear benefits, but unfortunately, the benefits from such activities remain elusive [54-58].

Physical activity especially cardio-type exercises have been shown to improve cognitive functions [59, 60]. Physical exercise may improve BP control and has been shown to increase neuroplasticity, improve blood flow, increase hemoglobin oxygen saturation, reduce inflammation, reduce the incidence of depression, and promote weight control [61, 62]. Physical exercise also decreases abdominal fat deposits, which have been linked to small vessel disease and brain ischemia [62]. Physical activity is often tied to weight loss, which has also been shown to improve cognitive functions [61, 62]. Chen et al. [63] noted that walking improves cognition in people diagnosed with AD. In their study, just
40 min of daily physical activity over a 12 -week period improved blood flow to the brain and increase neurogenesis in the hippocampal dentate gyrus [63].

In animal models, it has shown that exercise helps reduce the toxic effects of oxidative stress, which is associated with improvements in insulin resistance, reduced cholesterol, increased autonomic nervous system reactivity, and increased neurogenesis, all of which may affect cognitive abilities albeit in a non-specific manner [64-69].

\section{Primary Degenerative Dementia, Hypertension and the Aging Brain}

Dementia, an umbrella symptom, is often the end product of multiple neurodegenerative processes. The most common form of dementia, Alzheimer's disease, accounts for about 60 to $70 \%$ case of dementia [70, 71]. AD has been divided in multiple ways, but a common classification is further division into familial versus sporadic Alzheimer's disease, early onset Alzheimer's disease (diagnosis before age of 65), and late onset Alzheimer's disease diagnosed after age 65 [71]. $\mathrm{AD}$ evolves over many years, and is preceded by a prodromal state that is now recognized as mild cognitive impairment (MCI); MCI is itself heterogeneous, and not all cases of MCI impairment progress into Alzheimer disease [72, 73]. People diagnosed with MCI have about a incident risk of 10 to $15 \%$ per year progressing to Alzheimer's disease [72].

\section{Amyloid and Blood Pressure}

The full relationship between hypertension and $\beta$-amyloid burden and other variables such as clinical diagnosis of Alzheimer's disease and APOE status are quite complex [74, 75]; this field is also being revisited because advances in neuroimaging such as amyloid PET and now tau PET are enabling greater precision of diagnosis across clinical populations in line with new staging framework for $\mathrm{AD}[76,77]$.

At a simple level of resolution, it is known that hypertension doubles the risk of Alzheimer's disease [78]. The complexity of these overlapping relationships is highlighted by the findings from a clinical study of 259 normal controls and 79 clinical patients with AD conducted by Jeon et al. [75]. In one of their analyses of ApoE e4 carriers versus ApoE e4 noncarriers, hypertensive ApoE e4 carriers had an increased frequency of $\beta$-amyloid deposition and cortical thinning, common structural findings in $\mathrm{AD}$ [75]. The same findings were not noted in hypertensive ApoE e4 non-carriers. Clark et al. showed that persons with a combination of hypertension and increased $\beta$-amyloid burden had an accelerated cognitive decline when compared to either of the risk factors alone [79]. Yun et al. showed that persons with obstructive sleep apnea (a known risk factor for elevated BP) with increased $\beta$-amyloid deposition have an accelerated progressive cognitive decline 
course when compared to controls [80]. Gottesman et al. showed that midlife vascular risk factors including smoking, obesity, and hypertension were significantly associated with increased $\beta$-amyloid burden later in life [78].

An interesting finding in Gottesman et al. study was that vascular risk factors in older persons were not associated with increased $\beta$-amyloid burden [78]. Faraco and colleagues showed that hypertension increased the $\beta$ secretase activity resulting in increased $\beta$-amyloid 1 to 42 and increased $\beta$ amyloid 42/40 ratio [74]. Ashby et al. were able to demonstrate postmortem that hypertensive persons had greater $\beta$ amyloid burden compared to normotensive subjects [81]. Another interesting finding is that treated hypertensive persons may have increased $\beta$-amyloid burden compared to untreated hypertensives [82].

The relationship between hypertension and amyloid deposition may also be reciprocal. Hypertension is a risk factor for $\mathrm{AD}$, and hypertension has been noted with increased $\beta$ amyloid burden, which in turn is associated with the development of AD. $\beta$-amyloid often accumulates in the perivascular spaces leading to the disruption in the blood-brain barrier causing a dysregulation of brain homeostasis [82, 83] The damaged blood-brain barrier may affect cholinergic neurons whose terminals directly interact with foot processes of the astrocytes, which are an essential part of the blood-brain barrier. Parrotta et al. also noted that $\beta$-amyloid deposition led to neurotoxicity and neuronal death and that hypertension accelerates the deposition of microvascular $\beta$-amyloid [82].

\section{Mixed Dementia}

Mixed dementia is caused by the coexisting of multiple dementing pathologies (Alzheimer's, cerebrovascular disease, Lewy body disease, TDP 43 and others) in the same patient [84]. Although Zekry et al. noted controversy regarding the term mixed dementia, the Nun study showed subjects who meet the criteria for pathological Alzheimer's disease and also suffered cerebrovascular disease were more impaired $[85,86]$. As people age, those ages 85 years or older are frequently cognitively impaired, but the link between isolated AD pathology and cognitive decline become more clouded. The oldest Americans age 90 years and older showed higher prevalence of mixed pathology compared to their younger cohort ages 65 to 89 years [84].

\section{Hypertension and Tau}

The relationship between intracellular tau tangles and hypertension is also unclear. Kester et al. [87] showed that hypertension in the setting of homozygous ApoE e4 individuals was associated with higher CSF phospho tau 181 (p-tau181) and tau levels when compared to hypertensive people who either ApoE e4 non-carriers or heterozygous for ApoE e4 [87]. They concluded that hypertension has a detrimental effect on $\mathrm{AD}$ dementia pathology.

Glodzik et al. reviewed the impact effect of blood pressure in cognitively intact elderly people with and without hypertension. They noted that only people with hypertension who had an overall reduction in mean arterial pressure (MAP) showed decreased memory and increased CSF p-tau181 levels. In the entire study group ( $N=77$ followed for approximately 2 years) they noted an elevation in CSF p-tau181 and reduction in hippocampal volume [88]. Their overall conclusion was that the hypertensive group may be sensitive to blood pressure reductions.

Petrovitch et al. looked at the relation between midlife hypertension and pathologies associated with dementia in the Honolulu-Asia aging study [89]. They found that systolic blood pressure over $>160 \mathrm{mmHg}$ was associated with increased neuritic plaques and neurofibrillary plaques deposition throughout the cortices and hippocampus and lower total brain volume. In that study Diastolic blood pressure $>$ greater $95 \mathrm{mmHg}$ was associated with increased deposition of neurofibrillary tangles in the hippocampus [89]. The findings in that study were limited because of the lack of female participants.

Moonga et al. [90] reviewed AD patients with and without hypertension. They found that persons with AD and hypertension when compared to AD person without hypertension were more cognitively impaired, had greater burden of neuropsychiatric symptoms, and had greater hypometabolism in the hippocampus bilaterally. Interestingly, in their findings, they noted that hypertension did not affect the numbers of neuritic plaques and neurofibrillary tangles [90].

\section{New Blood Pressure Guidelines and Implementation}

Hypertension is ubiquitous in our society, and its effects on multiple organ systems and treatment remain a challenge. The 2017 guidelines introduced by the American College of Cardiology and American Heart Association Task force changed the parameters for hypertensive disease. The new criteria for diagnosis of stage 1 hypertension changed from 140 to $149 / 80$ to $89 \mathrm{mmHg}$ to 130 to $193 / 80$ to $89 \mathrm{mmHg}$ and for stage II from 150 to $159 / 90$ to $99 \mathrm{mmHg}$ to 140 to $149 /$ 90 to $99 \mathrm{mmHg}$ [91].

The reasoning for the change to new parameters was the linear relationship between elevated BP and strokes and heart disease [91]. Lamprea-Montelalegre et al. noted that with the new guidelines, more people would be diagnosed with hypertension leading to increased usage of antihypertensive medications and overall decrease in cardiovascular disease [92]. Smith et al. noted a decrease in cardiovascular disease and stroke in patients who were diagnosed with resistant hypertension and treated to the lower $\mathrm{BP}<130 / 80 \mathrm{mmHg}$ goal [93]. Sakima et al. also noted that intense BP control resulted in a significant reduction in stroke, heart attacks, and 
cardiovascular disease, and concluded that the BP target of $<$ $130 / 80 \mathrm{mmHg}$ is optimal [94]. Hajjar et al. looked at the effects of the new BP guidelines on the cognitive function of African-Americans and noted that BP targets $<130 / 80 \mathrm{mmHg}$ may result in improved outcomes regarding cognition in African-Americans [95].

Bakris et al. addressed some of the controversy regarding newer guidelines including that new stage 1 hypertensive patients might get pharmacological intervention without taking into account the 10-year risk of cardiovascular disease for these people [96]. They also noted that the new recommendations for BP control were the same for the young and elderly population, which could lead to adverse events in people with poor vascular compliance $[9,96]$. Those with poor vascular compliance had increases in dizziness and mentation when systolic BP was closer to $140 \mathrm{mmHg}$, a similar finding in the SPRINT study $[9,96]$. However, the latter study concluded that the new parameters will better benefit individuals that are at high risk for cardiovascular disease [96].

Kristnaswami et al. found that older adults with elevated pulse pressure whose BP was aggressively controlled resulted in more adverse events when compared to control in the SPRINT study [97].

Guidelines by themselves do not improve health and compliance with treatment. Ideally, BP control over long periods could be measured by summing the area under the BP curve as an integrative measure. Hypertensive disease does not have easily defined daily symptoms which makes it difficult for the hypertensive individual to appreciate the full impact of the disease on a regular basis. As a corollary to this situation, because the adverse effects of elevated BP do not manifest until much later (years to decades), outcome criteria of studies should not be the sole determinant of success in BP control over a short-term observation period.

Technological advances offer some hope for more sophisticated interventions. With the advent of smartphones, wearable or even implanted tech, and other similar devices, increasing treatment compliance and improvement in BP control might be considered feasible. Morawski et al. in their evaluation of healthcare mobile app showed an average decrease of $10 \mathrm{mmHg}$ in an intervention group versus control [98]. Ciemins et al. in a trial of home monitoring of BP combined smartphone technology and education, leading to improvement in mean BP control from 42 to $67 \%$ in the intervention group when compared to controls who showed improvement of mean BP control from 59 to $67 \%$ [99]. Milani et al. had a similar results, showing an increase in compliance and better BP control when technology was combined with education [100]. They noted that in traditional office-based care, the involvement by the patient is limited compared to technology-driven care in which there is an increased engagement or "treatment ownership" by the patient in their care [100]. Lu et al. looked at the role of telemedicine combined with nurse case management and found an average of $22.1 \mathrm{mmHg}$ reduction in systolic BP in linear regression analysis at 1 year [101]. Hedegaard et al. took a different approach to increase adherence by using a multifaceted pharmacistdriven program combined with motivational interviewing; they noted improvement in medication adherence in the intervention group versus control [102]. Green et al. looked at multiple combinations of technology and education compared to care as usual [103]. However, in their study, when they looked at home BP monitoring with web training only, they did not have a significant change in BP control compared to care as usual (36\% vs $31 \%$ respectively) [103]. But adding a web-based pharmacist to the home BP monitoring and web training group produced a significant change in BP control from 36 to $56 \%$ versus care as usual at $31 \%$ [102]. Technology helps people become more engaged in their care, but current technology alone does not appear sufficient to improve compliance and long-term outcome data is not yet available. As noted by both Green et al. and Hedegaard et al., education combined with healthcare providers are an integral part in the process of improving medication adherence and BP control [102]. The hope is that technology will help deliver and monitor care more closely allowing for a more immediate, personal, and direct care to the individual, although retaining goals such as improving overall health, morbidity, and mortality.

Dementia prevalence is also a growing public health problem in many societies, and the interactions of these two common disorders reveal new and complex relationships at the molecular, brain structure, individual, and population levels. Current and future studies are exploring the benefits of vascular risk factor reduction, which hold the promise of dementia prevention through well-established pharmacological and non-pharmacological interventions.

Required Author Forms Disclosure forms provided by the authors are available with the online version of this article.

\section{References}

1. Kumar J. Epidemiology of hypertension. Clinical Queries: Nephrology. 2013 Apr 1;2(2):56-61.

2. Ibrahim MM, Damasceno A. Hypertension in developing countries. The Lancet. 2012 Aug 11;380(9841):611-9.

3. Fryar CD, Ostchega Y, Hales CM, Zhang G, Kruszon-Moran D. Hypertension prevalence and control among adults: United States, 2015-2016. NCHS data brief. $2017 \operatorname{Oct}(289): 1-8$.

4. Thorin-Trescases N, de Montgolfier O, Pinçon A, Raignault A, Caland L, Labbé P, Thorin E. The impact of pulse pressure on cerebrovascular events leading to age-related cognitive decline. American Journal of Physiology-Heart and Circulatory Physiology. 2018 Feb 16. 
5. Cowley Jr AW. Long-term control of arterial blood pressure. Physiological reviews. 1992 Jan 1;72(1):231-300.

6. Li X, Lyu P, Ren Y, An J, Dong Y. Arterial stiffness and cognitive impairment. Journal of the neurological sciences. 2017 Sep $15 ; 380: 1-0$.

7. Wagenseil JE, Mecham RP. Elastin in large artery stiffness and hypertension. Journal of cardiovascular translational research. 2012 Jun 1;5(3):264-73.

8. Zebekakis PE, Nawrot T, Thijs L, Balkestein EJ, van der HeijdenSpek J, Van Bortel LM, Struijker-Boudier HA, Safar ME, Staessen JA. Obesity is associated with increased arterial stiffness from adolescence until old age. Journal of hypertension. 2005 Oct 1;23(10):1839-46.

9. SPRINT Research Group. A randomized trial of intensive versus standard blood-pressure control. New England Journal of Medicine. 2015 Nov 26;373(22):2103-16.

10. Clifford PS. Local control of blood flow. Advances in physiology education. 2011 Mar;35(1):5-15.

11. Chopra S, Baby C, Jacob JJ. Neuro-endocrine regulation of blood pressure. Indian journal of endocrinology and metabolism. 2011 Oct;15(Suppl4):S281.

12. Guzik TJ, Hoch NE, Brown KA, McCann LA, Rahman A, Dikalov S, Goronzy J, Weyand C, Harrison DG. Role of the T cell in the genesis of angiotensin II-induced hypertension and vascular dysfunction. Journal of Experimental Medicine. 2007 Oct 1;204(10):2449-60.

13. Schulz E, Gori T, Münzel T. Oxidative stress and endothelial dysfunction in hypertension. Hypertension Research. 2011 Jun;34(6): 665-673.

14. Montezano AC, Touyz RM. Molecular mechanisms of hypertension - reactive oxygen species and antioxidants: a basic science update for the clinician. Canadian Journal of Cardiology. 2012 May 1;28(3):288-95.

15. Harrison DG, Gongora MC. Oxidative stress and hypertension. Medical Clinics. 2009 May 1;93(3):621-35.

16. Bowler JV, Hachinski V. Vascular cognitive impairment: a new approach to vascular dementia. Bailliere's clinical neurology. 1995 Aug;4(2):357-76.

17. Petersen RC. Mild cognitive impairment: transition from aging to Alzheimer's disease. Alzheimer's disease: advances in etiology, pathogenesis and therapeutics. 2001 Mar 28:141-51.

18. Espeland MA, Probstfield J, Hire D, Redmon JB, Evans GW, Coday M, Lewis CE, Johnson KC, Wilmoth S, Bahnson J, Dulin MF. Systolic blood pressure control among individuals with type 2 diabetes: a comparative effectiveness analysis of three interventions. American journal of hypertension. $2015 \mathrm{Feb} 9 ; 28(8)$ : 995-1009.

19. de Havenon A, Majersik JJ, Tirschwell DL, McNally JS, Stoddard G, Rost NS. Blood pressure, glycemic control, and white matter hyperintensity progression in type 2 diabetics. Neurology. 2019 Mar 12;92(11):e1168-75.

20. Tillema JM, Renaud DL. Leukoencephalopathies in adulthood. In Seminars in neurology 2012 Feb (Vol. 32, No. 01, pp. 085-094). Thieme Medical Publishers.

21. Terry T, Raravikar K, Chokrungvaranon N, Reaven PD. Does aggressive glycemic control benefit macrovascular and microvascular disease in type 2 diabetes?: insights from ACCORD, ADVANCE, and VADT. Current cardiology reports. 2012 Feb 1;14(1):79-88.

22. Li G, Rhew IC, Shofer JB, Kukull WA, Breitner JC, Peskind E, Bowen JD, McCormick W, Teri L, Crane PK, Larson EB. Agevarying association between blood pressure and risk of dementia in those aged 65 and older: a community-based prospective cohort study. Journal of the American Geriatrics Society. 2007 Aug;55(8):1161-7.

23. Slavin MJ, Brodaty H, Sachdev PS. Challenges of diagnosing dementia in the oldest old population. Journals of Gerontology Series A: Biomedical Sciences and Medical Sciences. 2013 May 17;68(9):1103-11.

24. Forette F, Seux ML, Staessen JA, Thijs L, Babarskiene MR, Babeanu S, Bossini A, Fagard R, Gil-Extremera B, Laks T, Kobalava Z. The prevention of dementia with antihypertensive treatment: new evidence from the systolic hypertension in Europe (Syst-Eur) study. Archives of internal medicine. 2002 Oct 14;162(18):2046-52.

25. Peters R, Beckett N, Forette F, Tuomilehto J, Clarke R, Ritchie C, Waldman A, Walton I, Poulter R, Ma S, Comsa M. Incident dementia and blood pressure lowering in the Hypertension in the Very Elderly Trial cognitive function assessment (HYVETCOG): a double-blind, placebo controlled trial. The Lancet Neurology. 2008 Aug 1;7(8):683-9.

26. Williamson JD, Pajewski NM, Auchus AP, Bryan RN, Chelune G, Cheung AK, Cleveland ML, Coker LH, Crowe MG, Cushman WC, Cutler JA. Effect of intensive vs standard blood pressure control on probable dementia: a randomized clinical trial. Jama. 2019 Feb 12;321(6):553-61.

27. Nasrallah IM. A randomized trial of intensive versus standard systolic blood pressure control on brain structure: results from SPRINT MIND MRI. Alzheimer's \& Dementia: The Journal of the Alzheimer's Association. 2018 Jul 1;14(7):P1666.

28. Kivipelto M, Ngandu T. Good for the heart and good for the brain?. The Lancet. Neurology. 2019 Apr;18(4):327.

29. Sink KM, Leng X, Williamson J, Kritchevsky SB, Yaffe K, Kuller L, Yasar S, Atkinson H, Robbins M, Psaty B, Goff DC. Angiotensin-converting enzyme inhibitors and cognitive decline in older adults with hypertension: results from the Cardiovascular Health Study. Archives of internal medicine. 2009 Jul 13;169(13): 1195-202.

30. DeKosky ST, Fitzpatrick A, Ives DG, Saxton J, Williamson J, Lopez OL, Burke G, Fried L, Kuller LH, Robbins J, Tracy R. The Ginkgo Evaluation of Memory (GEM) study: design and baseline data of a randomized trial of Ginkgo biloba extract in prevention of dementia. Contemporary clinical trials. 2006 Jun 1;27(3):238-53.

31. Hughes TM, Sink KM. Hypertension and its role in cognitive function: current evidence and challenges for the future. American journal of hypertension. 2015 Nov 11;29(2):149-57.

32. Dufouil C, Chalmers J, Coskun O, Besancon V, Bousser MG, Guillon P, Macmahon S, Mazoyer B, Neal B, Woodward M, Tzourio-Mazoyer N. Effects of blood pressure lowering on cerebral white matter hyperintensities in patients with stroke: the PROGRESS (Perindopril Protection Against Recurrent Stroke Study) Magnetic Resonance Imaging Substudy. Circulation. 2005 Sep 13;112(11):1644-50.

33. Iadecola C. The pathobiology of vascular dementia. Neuron. 2013 Nov 20;80(4):844-66.

34. Schenk C, Wuerz T, Lerner AJ. Small vessel disease and memory loss: what the clinician needs to know to preserve patients' brain health. Current cardiology reports. 2013 Dec 1;15(12):427.

35. Román GC, Erkinjuntti T, Wallin A, Pantoni L, Chui HC. Subcortical ischaemic vascular dementia. The Lancet Neurology. 2002 Nov 1;1(7):426-36.

36. Hennessee JP, Reggente N, Cohen MS, Rissman J, Castel AD, Knowlton BJ. White matter integrity in brain structures supporting 
semantic processing is associated with value-directed remembering in older adults. Neuropsychologia. 2019 Apr 12.

37. van Norden AG, de Laat KF, Gons RA, van Uden IW, van Dijk EJ, van Oudheusden LJ, Esselink RA, Bloem BR, van Engelen BG, Zwarts MJ, Tendolkar I. Causes and consequences of cerebral small vessel disease. The RUN DMC study: a prospective cohort study. Study rationale and protocol. BMC neurology. 2011 Dec;11(1):29.

38. Kochunov P, Glahn DC, Lancaster J, Winkler A, Karlsgodt K, Olvera RL, Curran JE, Carless MA, Dyer TD, Almasy L, Duggirala R. Blood pressure and cerebral white matter share common genetic factors in Mexican Americans. Hypertension. 2011 Feb 1;57(2):330-5.

39. Khan U, Porteous L, Hassan A, Markus H. Risk factor profile of cerebral small vessel disease and its subtypes. Journal of Neurology, Neurosurgery \& Psychiatry. 2007 Jan 8.

40. Hassan A, Hunt BJ, O'sullivan M, Bell R, D'souza R, Jeffery S, Bamford JM, Markus HS. Homocysteine is a risk factor for cerebral small vessel disease, acting via endothelial dysfunction. Brain. 2004 Jan 1;127(1):212-9.

41. Pantoni L. Cerebral small vessel disease: from pathogenesis and clinical characteristics to therapeutic challenges. The Lancet Neurology. 2010 Jul 1;9(7):689-701.

42. Korczyn AD. Mixed dementia-the most common cause of dementia. Annals of the New York Academy of Sciences. 2002 Nov;977(1):129-34.

43. Schmidt R, Schmidt H, Haybaeck J, Loitfelder M, Weis S, Cavalieri M, Seiler S, Enzinger C, Ropele S, Erkinjuntti T, Pantoni L. Heterogeneity in age-related white matter changes. Acta neuropathologica. 2011 Aug 1;122(2):171-85.

44. Seiler S, Cavalieri M, Schmidt R. Vascular cognitive impairment - an ill-defined concept with the need to define its vascular component. Journal of the neurological sciences. 2012 Nov 15;322(1-2):11-6.

45. Greenberg SM, Vernooij MW, Cordonnier C, Viswanathan A, Salman RA, Warach S, Launer LJ, Van Buchem MA, Breteler MM, Microbleed Study Group. Cerebral microbleeds: a guide to detection and interpretation. The Lancet Neurology. 2009 Feb 1;8(2):165-74.

46. Sperling RA, Jack Jr CR, Black SE, Frosch MP, Greenberg SM, Hyman BT, Scheltens P, Carrillo MC, Thies W, Bednar MM, Black RS. Amyloid-related imaging abnormalities in amyloidmodifying therapeutic trials: recommendations from the Alzheimer's Association Research Roundtable Workgroup. Alzheimer's \& Dementia. 2011 Jul 1;7(4):367-85.

47. Jokinen H, Lipsanen J, Schmidt R, Fazekas F, Gouw AA, Van der Flier WM, Barkhof F, Madureira S, Verdelho A, Ferro JM, Wallin A. Brain atrophy accelerates cognitive decline in cerebral small vessel disease The LADIS study. Neurology. 2012 May 29;78(22):1785-92.

48. Price CC, Mitchell SM, Brumback B, Tanner JJ, Schmalfuss I, Lamar M, Giovannetti T, Heilman KM, Libon DJ. MRIleukoaraiosis thresholds and the phenotypic expression of dementia. Neurology. 2012 Aug 21;79(8):734-40.

49. Monet-Leprêtre M, Haddad I, Baron-Menguy C, Fouillot-Panchal M, Riani M, Domenga-Denier V, Dussaule C, Cognat E, Vinh J, Joutel A. Abnormal recruitment of extracellular matrix proteins by excess Notch3ECD: a new pathomechanism in CADASIL. Brain. 2013 May 6;136(6):1830-45.

50. Meschia JF. New information on the genetics of stroke. Current neurology and neuroscience reports. $2011 \mathrm{Feb}$ 1;11(1):35-41.
51. Meschia JF, Worrall BB, Rich SS. Genetic susceptibility to ischemic stroke. Nature Reviews Neurology. 2011 Jul;7(7):369.

52. Appel LJ. Lifestyle modification as a means to prevent and treat high blood pressure. Journal of the American Society of Nephrology. 2003 Jul 1;14(suppl 2):S99-102.

53. Skoog I, Korczyn AD, Guekht A. Neuroprotection in vascular dementia: a future path. Journal of the neurological sciences. 2012 Nov 15;322(1-2):232-6.

54. Nithianantharajah J, Hannan AJ. Mechanisms mediating brain and cognitive reserve: experience-dependent neuroprotection and functional compensation in animal models of neurodegenerative diseases. Progress in Neuro-Psychopharmacology and Biological Psychiatry. 2011 Mar 30;35(2):331-9.

55. Unverzagt FW, Guey LT, Jones RN, Marsiske M, King JW, Wadley VG, Crowe M, Rebok GW, Tennstedt SL. ACTIVE cognitive training and rates of incident dementia. Journal of the International Neuropsychological Society. 2012 Jul;18(4):66977.

56. Williams KN, Kemper S. Interventions to reduce cognitive decline in aging. Journal of psychosocial nursing and mental health services. 2010 May 1;48(5):42-51.

57. Schneider N, Yvon C. A review of multidomain interventions to support healthy cognitive ageing. The journal of nutrition, health \& aging. 2013 Mar 1;17(3):252-7.

58. Eyre H, Baune BT. Neuroimmunological effects of physical exercise in depression. Brain, behavior, and immunity. 2012 Feb 1;26(2):251-66.

59. Bridle C, Spanjers K, Patel S, Atherton NM, Lamb SE. Effect of exercise on depression severity in older people: systematic review and meta-analysis of randomised controlled trials. The British Journal of Psychiatry. 2012 Sep;201(3):180-5.

60. Karcher HS, Holzwarth R, Mueller HP, Ludolph AC, Huber R, Kassubek J, Pinkhardt EH. Body fat distribution as a risk factor for cerebrovascular disease: an MRI-based body fat quantification study. Cerebrovascular diseases. 2013;35(4):341-8.

61. Siervo M, Arnold R, Wells JC, Tagliabue A, Colantuoni A, Albanese E, Brayne C, Stephan BC. Intentional weight loss in overweight and obese individuals and cognitive function: a systematic review and meta-analysis. Obesity Reviews. 2011 Nov;12(11):968-83.

62. Chen WW, Zhang X, Huang WJ. Role of physical exercise in Alzheimer's disease. Biomedical reports. 2016 Apr 1;4(4):403-7.

63. Rouhl RP, Mertens AE, van Oostenbrugge RJ, Damoiseaux JG, Debrus-Palmans LL, Henskens LH, Kroon AA, de Leeuw PW, Lodder J, Cohen Tervaert JW. Angiogenic T-cells and putative endothelial progenitor cells in hypertension-related cerebral small vessel disease. Stroke. 2012 Jan;43(1):256-8.

64. Freitas H, Ferreira G, Trevenzoli I, Oliveira K, de Melo Reis R. Fatty acids, antioxidants and physical activity in brain aging. Nutrients. 2017 Nov;9(11):1263.

65. Park HS, Cho HS, Kim TW. Physical exercise promotes memory capability by enhancing hippocampal mitochondrial functions and inhibiting apoptosis in obesity-induced insulin resistance by high fat diet. Metabolic brain disease. 2018 Feb 1;33(1):283-92.

66. Musman J, Pons S, Barau C, Caccia C, Leoni V, Berdeaux A, Ghaleh B, Morin D. Regular treadmill exercise inhibits mitochondrial accumulation of cholesterol and oxysterols during myocardial ischemia-reperfusion in wild-type and ob/ob mice. Free Radical Biology and Medicine. 2016 Dec 1;101:317-24.

67. Ginty AT, Kraynak TE, Fisher JP, Gianaros PJ. Cardiovascular and autonomic reactivity to psychological stress: neurophysiological 
substrates and links to cardiovascular disease. Autonomic Neuroscience. 2017 Nov 1;207:2-9.

68. Nokia MS, Lensu S, Ahtiainen JP, Johansson PP, Koch LG, Britton SL, Kainulainen H. Physical exercise increases adult hippocampal neurogenesis in male rats provided it is aerobic and sustained. The Journal of physiology. 2016 Apr 1;594(7):185573.

69. Terry RD, Davies P. Dementia of the Alzheimer type. Annual review of neuroscience. 1980 Mar;3(1):77-95.

70. Awada A. Early and late-onset Alzheimer's disease: what are the differences?. Journal of neurosciences in rural practice. 2015 Jul 1;6(3):455.

71. Petersen RC, Lopez O, Armstrong MJ, Getchius TS, Ganguli M, Gloss D, Gronseth GS, Marson D, Pringsheim T, Day GS, Sager M. Practice guideline update summary: mild cognitive impairment: report of the guideline development, dissemination, and implementation subcommittee of the American Academy of Neurology. Neurology. 2018 Jan 16;90(3):126-35.

72. Petersen RC, Smith GE, Waring SC, Ivnik RJ, Tangalos EG, Kokmen E. Mild cognitive impairment: clinical characterization and outcome. Archives of neurology. 1999 Mar 1;56(3):303-8.

73. Faraco G, Park L, Zhou P, Luo W, Paul SM, Anrather J, Iadecola C. Hypertension enhances A $\beta$-induced neurovascular dysfunction, promotes $\beta$-secretase activity, and leads to amyloidogenic processing of APP. Journal of Cerebral Blood Flow \& Metabolism. 2016 Jan;36(1):241-52.

74. Jeon SY, Byun MS, Yi D, Lee JH, Choe YM, Ko K, Sohn BK, Choi HJ, Lee JY, Lee DY, KBASE Research Group. Influence of hypertension on brain amyloid deposition and Alzheimer's disease signature neurodegeneration. Neurobiology of aging. 2019 Mar $1 ; 75: 62-70$

75. Jack Jr CR, Bennett DA, Blennow K, Carrillo MC, Dunn B, Haeberlein SB, Holtzman DM, Jagust W, Jessen F, Karlawish J, Liu E. NIA-AA research framework: toward a biological definition of Alzheimer's disease. Alzheimer's \& Dementia. 2018 Apr 1;14(4):535-62.

76. Cummings J. The National Institute on Aging-Alzheimer's Association Framework on Alzheimer's disease: application to clinical trials. Alzheimer's \& Dementia. 2019 Jan 1;15(1):172-8.

77. Gottesman RF, Schneider AL, Zhou Y, Coresh J, Green E, Gupta N, Knopman DS, Mintz A, Rahmim A, Sharrett AR, Wagenknecht LE. Association between midlife vascular risk factors and estimated brain amyloid deposition. JAMA. 2017 Apr 11;317(14):1443-50.

78. Clark LR, Koscik RL, Allison SL, Berman SE, Norton D, Carlsson CM, Betthauser TJ, Bendlin BB, Christian BT, Chin NA, Asthana S. Hypertension and obesity moderate the relationship between $\beta$-amyloid and cognitive decline in midlife. Alzheimer's \& Dementia. 2018 Oct 25.

79. Yun CH, Lee HY, Lee SK, Kim H, Seo HS, Bang S, Kim SE, Greve DN, Au R, Shin C, Thomas RJ. Amyloid burden in obstructive sleep apnea. Journal of Alzheimer's Disease. 2017 Jan 1;59(1):21-9.

80. Ashby EL, Miners JS, Kehoe PG, Love S. Effects of hypertension and anti-hypertensive treatment on amyloid- $\beta(A \beta)$ plaque load and $A \beta$-synthesizing and $A \beta$-degrading enzymes in frontal cortex. Journal of Alzheimer's Disease. 2016 Jan 1;50(4):1191-203.

81. Perrotta M, Lembo G, Carnevale D. Hypertension and dementia: epidemiological and experimental evidence revealing a detrimental relationship. International journal of molecular sciences. 2016 Mar 8;17(3):347.
82. Montagne A, Zhao Z, Zlokovic BV. Alzheimer's disease: a matter of blood-brain barrier dysfunction?. Journal of Experimental Medicine. 2017 Nov 6;214(11):3151-69.

83. James BD, Bennett DA, Boyle PA, Leurgans S, Schneider JA. Dementia from Alzheimer disease and mixed pathologies in the oldest old. Jama. 2012 May 2;307(17):1798-800.

84. Snowdon DA, Greiner LH, Mortimer JA, Riley KP, Greiner PA, Markesbery WR. Brain infarction and the clinical expression of Alzheimer disease: the Nun Study. Jama. 1997 Mar 12;277(10): 813-7.

85. Zekry D, Hauw JJ, Gold G. Mixed dementia: epidemiology, diagnosis, and treatment. Journal of the American Geriatrics Society. 2002 Aug 1;50(8):1431-8.

86. Kester MI, van der Flier WM, Mandic G, Blankenstein MA, Scheltens P, Muller M. Joint effect of hypertension and APOE genotype on CSF Biomarkers For Alzheimer's disease. Alzheimer's \& Dementia: The Journal of the Alzheimer's Association. 2009 Jul 1;5(4):e17.

87. Glodzik L, Rusinek H, Pirraglia E, McHugh P, Tsui W, Williams S, Cummings M, Li Y, Rich K, Randall C, Mosconi L. Blood pressure decrease correlates with tau pathology and memory decline in hypertensive elderly. Neurobiology of aging. 2014 Jan 1;35(1):64-71.

88. Petrovitch H, White LR, Izmirilian G, Ross GW, Havlik RJ, Markesbery W, Nelson J, Davis DG, Hardman J, Foley DJ, Launer LJ. Midlife blood pressure and neuritic plaques, neurofibrillary tangles, and brain weight at death: the HAAS is. Neurobiology of aging. 2000 Jan 1;21(1):57-62.

89. Moonga I, Niccolini F, Wilson H, Pagano G, Politis M, Alzheimer's Disease Neuroimaging Initiative. Hypertension is associated with worse cognitive function and hippocampal hypometabolism in Alzheimer's disease. European journal of neurology. 2017 Sep;24(9):1173-82.

90. Whelton PK, Carey RM, Aronow WS, Casey DE, Collins KJ, Himmelfarb CD, DePalma SM, Gidding S, Jamerson KA, Jones DW, MacLaughlin EJ. 2017 ACC/AHA/AAPA/ABC/ACPM/ AGS/APhA/ASH/ASPC/NMA/PCNA guideline for the prevention, detection, evaluation, and management of high blood pressure in adults: a report of the American College of Cardiology/ American Heart Association Task Force on Clinical Practice Guidelines. Journal of the American College of Cardiology. 2018 May 7;71(19):e127-248.

91. Lamprea-Montealegre JA, Zelnick LR, Hall YN, Bansal N, de Boer IH. Prevalence of hypertension and cardiovascular risk according to blood pressure thresholds used for diagnosis. Hypertension. 2018 Sep;72(3):602-9.

92. Smith SM, Gurka MJ, Calhoun DA, Gong Y, Pepine CJ, CooperDeHoff RM. Optimal systolic blood pressure target in resistant and non-resistant hypertension: a pooled analysis of patient-level data from SPRINT and ACCORD. The American journal of medicine. 2018 Dec 1;131(12):1463-72.

93. Sakima A, Satonaka H, Nishida N, Yatsu K, Arima H. Optimal blood pressure targets for patients with hypertension: a systematic review and meta-analysis. Hypertension Research. 2019 Apr;42(4):483.

94. Hajjar I, Rosenberger KJ, Kulshreshtha A, Ayonayon HN, Yaffe $\mathrm{K}$, Goldstein FC. Association of JNC-8 and SPRINT systolic blood pressure levels with cognitive function and related racial disparity. JAMA neurology. 2017 Oct 1;74(10):1199-205.

95. Bakris G, Sorrentino M. Redefining hypertension - assessing the new blood-pressure guidelines. New England Journal of Medicine. 2018 Feb 8;378(6):497-9. 
96. Krishnaswami A, Kim DH, McCulloch CE, Forman DE, Maurer MS, Alexander KP, Rich MW. Individual and joint effects of pulse pressure and blood pressure treatment intensity on serious adverse events in the SPRINT trial. The American Journal of Medicine. 2018 Oct 1;131(10):1220-7.

97. Morawski K, Ghazinouri R, Krumme A, McDonough J, Durfee E, Oley L, Mohta N, Juusola J, Choudhry NK. Rationale and design of the Medication adherence Improvement Support App For Engagement-Blood Pressure (MedISAFE-BP) trial. American heart journal. 2017 Apr 1;186:40-7.

98. Ciemins, Elizabeth L., Anupama Arora, Nicholas C. Coombs, Barbara Holloway, Elizabeth J. Mullette, Robin Garland, Shannon Bishop-Green, Jerry Penso, and Patricia J. Coon. "Improving blood pressure control using smart technology." Telemedicine and e-Health 24, no. 3 (2018): 222-228.

99. Milani RV, Lavie CJ, Bober RM, Milani AR, Ventura HO. Improving hypertension control and patient engagement using digital tools. The American journal of medicine. 2017 Jan 1;130(1):14-20.
100. Lu JF, Chen CM, Hsu CY. Effect of home telehealth care on blood pressure control: A public healthcare centre model. Journal of telemedicine and telecare. 2019 Jan;25(1):35-45.

101. Hedegaard U, Hallas J, Ravn-Nielsen LV, Kjeldsen LJ. Processand patient-reported outcomes of a multifaceted medication adherence intervention for hypertensive patients in secondary care. Research in Social and Administrative Pharmacy. 2016 Mar 1;12(2):302-18.

102. Green BB, Cook AJ, Ralston JD, Fishman PA, Catz SL, Carlson J, Carrell D, Tyll L, Larson EB, Thompson RS. Effectiveness of home blood pressure monitoring, Web communication, and pharmacist care on hypertension control: a randomized controlled trial. JAMA. 2008 Jun 25;299(24):2857-67.

Publisher's Note Springer Nature remains neutral with regard to jurisdictional claims in published maps and institutional affiliations. 